\title{
Value and Financial Toxicity of New Cancer Drugs
}

RITA J. WICKHAM, PhD, RN, AOCN ${ }^{\circledast}$

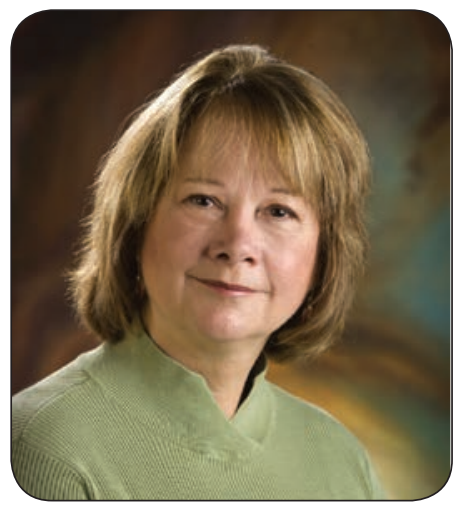

ated with PDT-issues not addressed in any CLEOPATRA publications.

During CLEOPATRA, investigators would not know the future price of pertuzumab, although trastuzumab cost approximately $\$ 70,000$ a year. Durkee and others (2016) carried out Markov analyses to predict the "cost of progress." Averaged across treatment, the cost to insurers and patients receiving PDT would be $\$ 4,649$ per week. For a median survival of 39.4 months for DT and 56.9 months for PDT, drug costs of $\$ 347,627$ and $\$ 805,449$, respectively, were predicted-plus other drugs, administration, laboratory, etc. If all 17,450 patients diagnosed with advanced HER2+ breast cancer each year got PDT or DT, now recommended by the National Comprehensive Cancer Network (NCCN, 2016) as first-line treatment for metastatic, HER2+ breast cancer, yearly costs would be billions, which Durkee concluded is not sustainable in the United States.

\section{VALUE AND COST/BENEFIT}

Value and cost/benefit of cancer drugs became "front page" in a publication by 116 hematologists that discussed drug prices for chronic myelogenous leukemia (CML) and declared cancer drug prices are too high, untenable, may block patients' access to therapy, and are detrimental to US health care (Experts in Chronic Myeloid Leukemia, 2013). High cancer drug costs began in 2001 with the approval of imatinib. Some drug companies argue that high research and development (R\&D) costs must cover costs of unsuccessful drugs. However, most basic new drug research is done in universities and small biomedical firms. Then, 
pharmaceutical companies buy the new agent or biotech firm and pay clinical trials costs (Lexchin, 2012). Combined research efforts have increased 10 -year CML survival from $20 \%$ to $80 \%$, and many patients have near-normal life expectancies if they (and their insurer) continue to pay for their tyrosine kinase inhibitor. This is a pressing issue: Direct annual medical costs for cancer care are approximately $\$ 86$ billion and are among the most rapidly growing spending disease groups (ASCO, 2015).

Imatinib initially cost $\sim \$ 30,000$ a year; $R \& D$ costs would have been recouped in 2 years (Love, 2013). It seems the current price of imatinib should be about the same or slightly lower (because of competition from new drugs), or perhaps a little higher to reflect modest inflation of the past decade. But imatinib costs $>\$ 150,000$ per year, a $>500 \%$ price increase (GoodRx, 2016a)-2014 total sales were $\$ 4.746$ billion dollars (PMLiVE, 2016).

Increasing drug costs are not limited to cancer; US branded prescription drug prices increased $10.9 \%$ in 2014 and $14.8 \%$ in 2015 , while inflation rose $1.6 \%$ and $1.5 \%$, respectively (Dennis, 2016; The World Bank, 2016). Drug spending was $\$ 297.7$ billion in 2014; a third of that cost was new hepatitis C drugs. Cancer drugs cost significantly more in the Unites States than in other developed countries (CML Experts, 2013). Novartis had been able to protect patent rights and fend off generic versions of imatinib in the United States, but generics are available in other countries and one received US FDA approval in February 2016.

\section{SOLID TUMORS}

The value dilemma is greater for drugs indicated for patients with advanced solid tumors, such as nivolumab (Opdivo), approved for patients with advanced nonsquamous non-small cell lung cancer (Borghaei et al., 2015). Patients in the pivotal phase III study, who ultimately died, were randomly assigned to receive palliative nivolumab or docetaxel. Response rates-evaluated after 2.5 months-were modest (as expected in previously treated patients with metastatic disease), 19\% with nivolumab and $12 \%$ with docetaxel $(p=.02)$. Overall rates of adverse effects were similar, but serious events with nivolumab included thyroid, pulmonary, hepatic, colon, and renal effects. Most patients progressed while on study and went on to receive $\geq 1$ other therapies that probably influenced survival. This study was funded, developed, implemented, analyzed, and reported with pharmaceutical company sponsorship (Borghaei et al., 2015). Of the 792 patients enrolled in the study, 582 were randomized. The authors stated most of the other 210 patients "no longer met inclusion criteria" but provided no further explanation, and these patients were not included in the intentto-treat analysis. Median overall survival with nivolumab was 12.2 vs. 9.4 months with docetaxel, a statistically significant difference $(p=.002)$. Clinicians must help patients determine if this is clinically significant.

Nivolumab costs $\sim \$ 15,000 /$ month (GoodRx, 2016b). The cost to treat 100 patients for 3 months to identify 20 responders is $\sim \$ 4,500,000$, so the true cost of palliative nivolumab is $\$ 225,000$ for each responder in the period. What is the value of 3 months' survival in $20 \%$ of nivolumab-treated patients, who may experience major toxicity?

\section{AP ROLES}

Advanced practitioners guide their patients through cancer diagnosis and treatment, and they educate and manage symptoms as well. But frank discussion of treatment costs is rapidly becoming integral to patient care. Advanced practitioners must familiarize themselves with ASCO's Value Framework that emphasizes providing high-quality patient care and facilitates shared decision-making about the value of expensive diagnostic tests and new treatments, as well as becoming stakeholders to grapple with these issues (Schnipper et al., 2015). 


\section{References}

American Society of Clinical Oncology. (2015). The state of cancer care in America, 2015: A report by the American Society of Clinical Oncology. Journal of Oncology Practice, 11, 79-113.

Baselga, J., Cortés, J., Kim, S.-B., Im, S.-A., Hegg, R., Im, Y.H.,...Swain, S. M. (2012). Pertuzumab plus trastuzumab plus docetaxel or metastatic breast cancer. New England Journal of Medicine, 366, 109-119.

Borghaei, H., Paz-Ares, L., Horn, L., Spigel, D. R., Steins, M., Ready, N. E.,...Brahmer, J. R. (2015). Nivolumab versus docetaxel in advanced nonsquamous non-small-cell lung cancer. New England Journal of Medicine, 373, 16271639. http://dx.doi.org/10.1056/NEJMoa1507643

Dennis, B. (2016). Prescription drug prices jumped more than 10 percent in 2015, analysis finds. Retrieved from https:// www.washington post.com/news/to-your-health/ $\mathrm{wp} / 2016 / 01 / 11 /$ prescription-drug-prices-jumpedmore-than-10-percent-in-2015/

Durkee, B. Y., Qian, Y., Pollom, E. L., King, M. T., Dudley, S. A., Shaffer, J. L.,...Horst, K. C. (2016). Cost-effectiveness of pertuzumab in human epidermal growth factor receptor 2-positive metastatic breast cancer. Journal of Clinical Oncology, 34, 902-909 [E-pub ahead of print 8 Sept 2015]. http://dx.doi.org/10.1200/JCO.2015.62.9105

Experts in Chronic Myeloid Leukemia. (2013). The price of drugs for chronic myeloid leukemia (CML) is a reflection of the unsustainable prices of cancer drugs: From the perspective of a large group of CML experts. Blood, 121, 4439-4442. http://dx.doi.org/10.1182/ blood-2013-03-490003

GoodRx. 2016b. Prices and coupons for 6 vials (10ml) of Opdivo $100 \mathrm{mg} / 10 \mathrm{ml}$. Retrieved from http://www.goodrx. com/opdivo

GoodRx. 2016a. Prices and coupons for 60 tablets of Gleevec 100mg. Retrieved from http://www.goodrx.com/gleevec

Herold, K. (2016). Review of CLEOPATRA. Journal of the Advanced Practitioner in Oncology, 7, 83-89.

Lexchin, J. (2012). Those who have the gold make the evidence: How the pharmaceutical industry biases the outcomes of clinical trials of medications. Science and Engineering Ethics, 18, 247-261. http://dx.doi.org/10.1007/ s11948-011-9265-3

Love, J. (2013). R\&D costs for Gleevec. Retrieved from http:// www.keionline.org/node/1697

National Comprehensive Cancer Network. (2016). NCCN Clinical Practice Guidelines in Oncology: Breast cancer. Version 1.2016.

PMLiVE. 2016. Top 50 pharmaceutical products by global sales. Retrieved from http://www.pmlive.com/top_pharma_list/pharmaceutical_products/gleevec_glivec

Schnipper, L. E., Davidson, N. E., Wollins, D. S., Tyne, C., Blayney, D. W., Blum, D.,...Schilsky, R. L. (2015). American Society of Clinical Oncology statement: A conceptual framework to assess the value of cancer treatment options. Journal of Clinical Oncology, 33, 2563-2577. http:// dx.doi.org/10.1200/JCO.2015.61.6706

Swain, S. M., Baselga, J., Kim, S.-B., Ro, J., Semiglazov, V., Campone, M.,...Cortés, J. (2015). Pertuzumab, trastuzum$\mathrm{ab}$, and docetaxel in HER2-positive metastatic breast cancer. New England Journal of Medicine, 372, 724-734. http://dx.doi.org/10.1016/S1470-2045(13)70130-X

The World Bank. (2016). Inflation, consumer prices (annual \%). Retrieved from http://data.worldbank.org/indicator/ FP.CPI.TOTL.ZG 